
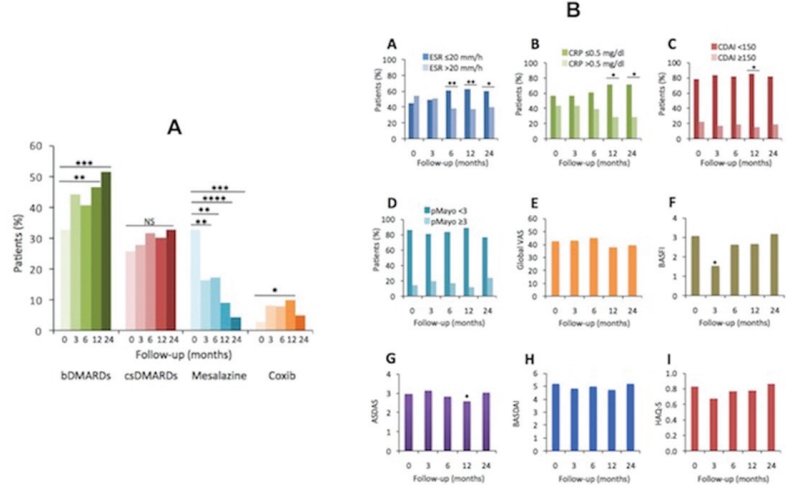

Conclusions: A multidisciplinary approach can improve in the therapeutic management and outcome (e.g. disease activity measures) of eSpA patients. bDMARD use paralleled an improvement in disease measures and confirmed a good safety profile.

Disclosure of Interest: None declared

DOI: 10.1136/annrheumdis-2018-eular.3513

\section{SAT0267 EFFICACY AND SAFETY OF BCD-055, PROPOSED INFLIXIMAB BIOSIMILAR, COMPARED TO INFLIXIMAB: 54-WEEK RESULTS FROM ASART-2 PHASE 3 CLINICAL STUDY}

L. Denisov ${ }^{1}$, P. Shesternya ${ }^{2}$, T. Plaksina ${ }^{3}$, T. Kropotina ${ }^{4}$, N. Soroka ${ }^{5}$, E. Kunder ${ }^{5}$, A. Lutskii ${ }^{6}$, A. Eremeeva ${ }^{6}$, E. Dokukina $^{6}$, E. Chernyaeva $^{6}$, R. Ivanov ${ }^{6}$, V. Mazurov $^{7}$ ${ }^{1}$ V.A.Nasonova Research Institute of Rheumatology, Moscow; ${ }^{2}$ Professor V.F. Voyno-Yasenetskiy Krasnoyarsk State Medical University, Krasnoyarsk; ${ }^{3}$ Regional Clinical Hospital, Nizhniy Novgorod; ${ }^{4}$ Regional Clinical Hospital, Omsk, Russian Federation; ${ }^{5}$ Clinical Hospital №9, Minsk, Belarus; ${ }^{6}$ JCS BIOCAD, SaintPetersburg; ${ }^{7}$ North-Western State Medical University named after I.I. Mechnikov, Moscow, Russian Federation

Background: Non-inferiority of BCD-055 in direct comparison to infliximab originator after 30 weeks of treatment in patients with ankylosing spondylitis (AS) was shown previously ${ }^{1}$. Here we present 54 week safety and efficacy data in ITT population from international double-blind randomised ASART-2 clinical trial.

Objectives: To compare BCD-055, proposed infliximab biosimilar and infliximab originator in terms of efficacy and safety in patients with AS.

Methods: Adult patients $(n=199)$ aged $18-65$ years, with active AS (BASDAl>4) received $5 \mathrm{mg} / \mathrm{kg}$ of $B C D-055(n=132)$ or infliximab $(n=67)$ IV on w0, w2 and w6 and then every $8 \mathrm{w}$ until $\mathrm{w} 54$. The results of the primary endpoint assessment (ASAS20 at w30) were presented earlier ${ }^{1}$. Secondary endpoints were proportion of patients, achieved ASAS20/40, and mean change from baseline in BASDAI, BASMI, BASFI, MASES, SF36 scores, chest excursion and $\mathrm{TJC}^{44}$ at w54. Rate of AEs and proportion of patient with ADA to infliximab in both groups were also evaluated.

Results: The proportions of patients achieved ASAS20/ASAS40 were similar in both study groups at w54 (Abstract SAT0267 - figure 1).. Improvement in AS symptoms showed similar dynamics in both groups: significant decrease in AS activity (BASDAI) and improvement in other secondary endpoints has developed within the first 14 weeks of treatment in both study groups and remained at achieved level until w54. The magnitude of changes of all evaluated parameters did not differ between groups.

No statistically significant differences in rates of AEs were found between study groups (table 1). Most common reported AEs were infections, hematologic and vascular disorders, hypersensitivity reactions. Formation of ADA to infliximab was detected with similar frequency in both groups.

Abstract SAT0267 - Table 1. 54 w safety data

\begin{tabular}{lccc}
\hline & $\begin{array}{c}\text { BCD-055, } \mathbf{n} \\
(\%)\end{array}$ & $\begin{array}{c}\text { Infliximab, } \mathbf{n} \\
(\%)\end{array}$ & $\begin{array}{c}\mathbf{p} \\
\text { value }\end{array}$ \\
\hline Any AE/SAE & $82(62.12)$ & $43(64.18)$ & 0.898 \\
Any SAE & $7(5.30)$ & $5(7.46)$ & 0.376 \\
Therapy-related AE/SAE & $40(30.30)$ & $26(38.81)$ & 0.296 \\
Therapy-related SAE & $5(3.79)$ & $4(5.97)$ & 0.489 \\
Any SAE/AE grade 3-5 & $18(13.64)$ & $11(16.42)$ & 0.754 \\
Therapy-related AE grade 3-5 & $11(8.33)$ & $7(10.45)$ & 0.818 \\
Treatment withdrawal due to SAE/AE & $11(8.33)$ & $7(10.45)$ & 0.818 \\
Deaths & $1(0.76)$ & $0(0)$ & 1.000 \\
ADA positive & $27(21.26)$ & $13(20,63)$ & 0.920 \\
ADA positive, confirmed by neutralisation & $4(3.15)$ & $4(6.35)$ & 0.443 \\
assay & & & \\
\hline
\end{tabular}

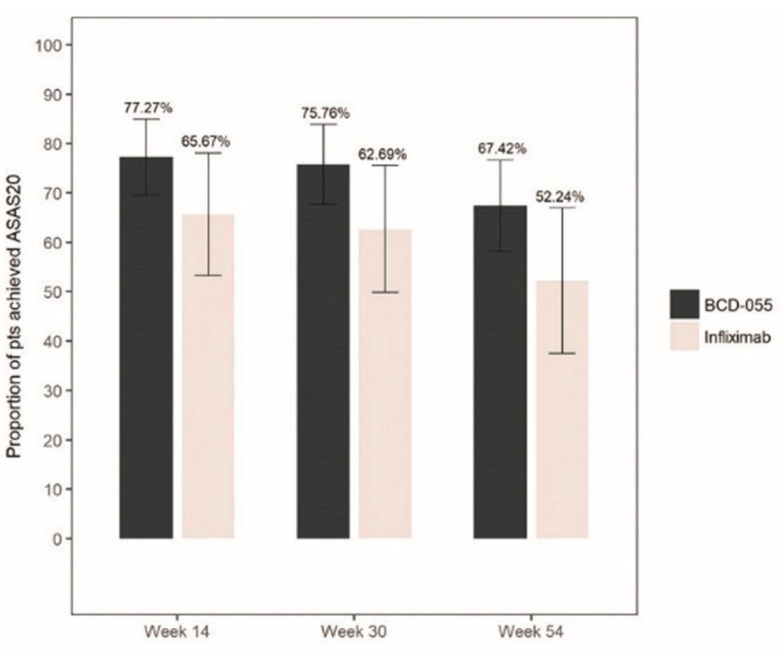

Abstract SAT0267 - Figure 1. Proportion of patients achieved ASAS20 at weeks 14, 30 and $54(\%, 95 \% \mathrm{Cl})$.

Conclusions: The 54 week results supports previously confirmed similar efficacy and safety of BCD-055, proposed infliximab biosimilar, and infliximab originator in patients with active AS. At all evaluated time points the efficacy as well as rate of AEs/SAEs did not differ between BCD-055 and infliximab originator groups.

\section{REFERENCE:}

[1] Denisov L, Gordeev I, Mazurov V, et al. FRI0208 Comparison of efficacy, safety and pharmacokinetics of infliximab biosimilar (BCD-055) and innovator infliximab Ann Rheum Dis 2017;76:560-561.

Disclosure of Interest: L. Denisov: None declared, P. Shesternya: None declared, T. Plaksina: None declared, T. Kropotina: None declared, N. Soroka: None declared, E. Kunder: None declared, A. Lutskii Employee of: JSC BIOCAD, A. Eremeeva Employee of: JSC BIOCAD, E. Dokukina Employee of: JSC BIOCAD, E. Chernyaeva Employee of: JSC BIOCAD, R. Ivanov Employee of: JSC BIOCAD, V. Mazurov: None declared DOI: 10.1136/annrheumdis-2018-eular.2390

\section{SAT0268 SECUKINUMAB DEMONSTRATES LOW RADIOGRAPHIC PROGRESSION AND SUSTAINED EFFICACY THROUGH 4 YEARS IN PATIENTS WITH ACTIVE ANKYLOSING SPONDYLITIS}

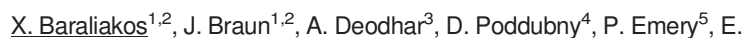

M. Delicha ${ }^{6}$, Z. Talloczy ${ }^{7}$, B. Porter ${ }^{8} .{ }^{1}$ Rheumazentrum Ruhrgebiet, Herne; ${ }^{2}$ Ruhr University, Bochum, Germany; ${ }^{3}$ Oregon Health and Science University, Portland, USA; ${ }^{4}$ Charité Universitätsmedizin Berlin, Berlin, Germany; ${ }^{5}$ University of Leeds, Leeds, UK; ${ }^{6}$ Novartis Pharma AG, Basel, Switzerland; ${ }^{7}$ Novartis Pharmaceuticals Corporation, East Hanover, USA; ${ }^{8}$ Novartis Pharmaceuticals Corporation, East Hanover, Switzerland

Background: The MEASURE 1 core trial reported improved signs and symptoms of ankylosing spondylitis (AS) with secukinumab, a fully human anti-interleukin17 A monoclonal antibody. $^{1}$

Objectives: To assess efficacy, including imaging outcomes, and safety from the MEASURE 1 extension trial (NCT01863732) up to 4 years.

Methods: Patients (pts) had completed 104 wks (2 years) in the core study with SC secukinumab 150 (IV $\rightarrow 150 \mathrm{mg}$ ) or $75 \mathrm{mg}$ (IV $\rightarrow 75 \mathrm{mg}$ ) every $4 \mathrm{wks}$, following IV loading to Wk4, or placebo to Wk16/24. Efficacy data at Wk208 are reported for pts originally randomised to secukinumab $150 \mathrm{mg}$ (approved dose). Lateral cervical and lumbar spine radiographs were assessed with the modified Stoke Ankylosing Spondylitis Spinal Score (mSASSS), and MRIs with the Berlin SI joint total oedema score and Berlin spine score (derived from ASspi-MRI-a results). Images were evaluated by 2 central readers blinded to treatment/visit; mean scores were used. Descriptive statistics on observed/imputed data are provided.

Results: Of the 274 pts enrolled in this extension study, $89.7 \%(78 / 87)$ originally assigned to secukinumab $150 \mathrm{mg}$ completed 208 wks. $\Delta$ mSASSS (mean \pm SD) from baseline (BL) to Wk208 was numerically lower with secukinumab $150 \mathrm{mg}$ $(1.2 \pm 3.91)$ vs $75 \mathrm{mg}(1.7 \pm 4.70)$. No definite radiographic progression ( $\triangle \mathrm{mSASSS}$ from $B L<2$ ) was seen in $79 \%$ of pts on secukinumab 150 mg over 208 wks (figure 1). Mean $\Delta$ mSASSS at Wk208 was numerically higher in males, and in pts with 